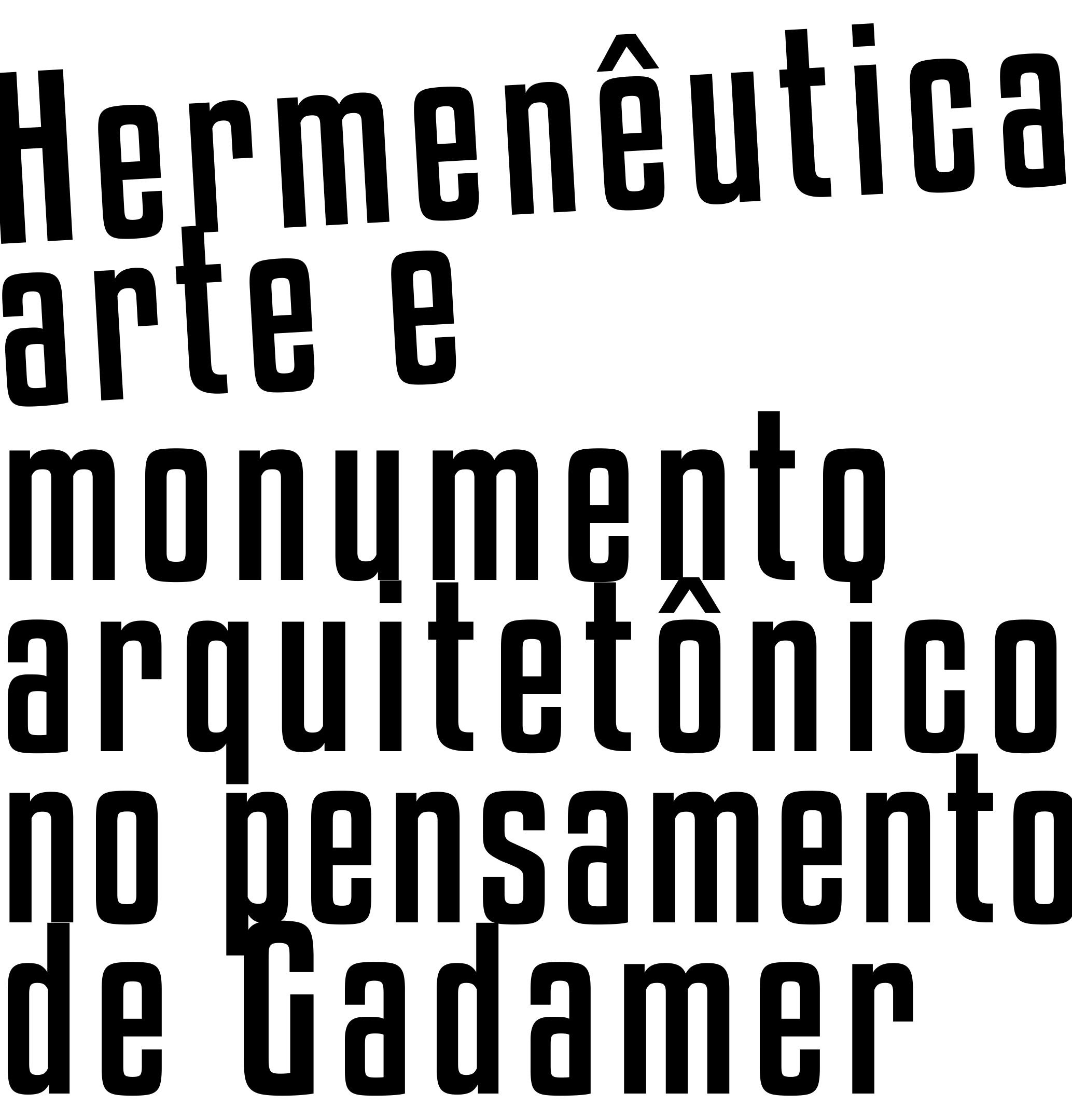




\title{
Hermenêutica, arte e monumento arquitetônico no pensamento de Gadamer
}

\author{
Katharynne Norrana Damasceno de Jesus ${ }^{1}$ \\ Universidade Federal do Piauí
}

\footnotetext{
1. Ao tempo da submissão, aluna do curso de Arquitetura e Urbanismo, com pesquisa financiada pelo PIBIC CNPq (IC) e orientada pelo Prof. Dr. Gustavo Silvano Batista.
}

RESUMO: Este estudo investiga o conceito gadameriano de monumento arquitetônico, apresentado em Verdade e método. Apesar de se referir ao monumento arquitetônico apenas em trechos de sua obra, Gadamer insere a arquitetura no contexto das obras de arte, situando-a em uma posição exemplar dentre as outras expressões artísticas no processo de compreensão da verdade. Sendo assim, a pesquisa objetivou traçar um estudo da noção gadameriana de monumento arquitetônico e, consequentemente, inserir a problemática hermenêutica no estudo da arquitetura. A metodologia se caracterizou por ser essencialmente bibliográfica. Percebeu-se que a visão de Gadamer sobre a arquitetura é como local de abrigo de todas as artes. Esta, quando consegue suprir seu aspecto funcional e artístico, pode ser denominada de monumento arquitetônico: a arquitetura como obra de arte. Almeja-se portanto, estreitar o vínculo existente entre filosofia e arquitetura, a fim de indicar novas perspectivas para a compreensão da arte da construção.

PALAVRAS-CHAVE: hermenêutica filosófica; arquitetura; Gadamer; monumento arquitetônico. 


\section{INTRODUÇÃO}

No contexto do pensamento europeu, Hans-Georg Gadamer foi um filósofo da tradição alemã frequentemente descrito como herdeiro de Kant, Husserl e Heidegger, de quem recebeu influência não somente no embasamento de muitos de seus pensamentos, mas também no parâmetro de contestação e diálogo. Sua filosofia é voltada para a reflexão sobre a arte como caminho para a compreensão da verdade, enquanto questionamento da hermenêutica filosófica, e para os padrões de experiência e compreensão.

Gadamer insere uma alternativa de consideração da obra de arte e seu conteúdo em um cenário histórico-filosófico do "fim da arte", no século XIX. Esse período, durante o qual foi necessário lidar com as consequências da Revolução Industrial, é caracterizado pela ascensão das diversas áreas do conhecimento e grande euforia tecnológica, bem como pelo interesse por assuntos de cunho estético e científico. No contexto artístico, rupturas provocaram mudanças na situação em que viviam e trabalhavam os artistas:

Agora, os alicerces em que a arte assentara durante toda a sua existência estavam sendo abalados de um outro modo. A Revolução Industrial começou a destruir as próprias tradições do sólido artesanato; o trabalho manual 
cedia lugar à produção mecânica, a oficina cedia passo à fábrica. (GOMBRICH, 2012, p. 499)

As noções de normas estabelecidas, de convenções de estilo e, consequentemente, de segurança foram perdidas no século XIX. O artista não reconhecia mais seu lugar em um mundo com uma ampla gama de opções, no qual o gosto do criador nem sempre coincidia com o do público e, em consequência, a "arte" passou a sofrer mascaramentos e o gosto popular deu espaço à sua deterioração (GOMBRICH, 2012). Nessa conjuntura, o individualismo e o cenário industrial fazem emergir vanguardas que contestam as mudanças sociais e as expressões artísticas vigentes. Assim, o século XIX se torna "o marco em que se dá a mudança violenta de cenário da crise do clássico renascentista e a ascensão da arte moderna" (ARGULLOL, 1991, p. 6, tradução nossa).

A suposta ideia de fim da arte no mundo moderno representa a ruptura do equilíbrio entre a matéria e o espírito representados na arte clássica. A universalização da informação torna-se a "realização pervertida do triunfo do espírito absoluto" de Hegel (VATTIMO, 1996, p. 39), a manifestação da totalidade das coisas. As práticas vanguardistas dão espaço para uma explosão estética que ultrapassa a tradição e gera uma reviravolta na avaliação, na exposição e na criação da obra de arte: o lugar da arte já não é mais o pensado tradicionalmente para a experiência estética, sendo sua capacidade de problematização o critério de avaliação do seu êxito.

A morte da arte é, portanto, a morte dos critérios de avaliação e dos cânones tradicionais que permitiam que o artista e o observador apreciassem o belo e tomassem conta de sua sacralidade. A arte então passa a encarar uma gama de opções que não só admitem o belo, como também o contestam. É nesse contexto conflituoso entre a tradição e o moderno que Gadamer constrói uma ponte entre ambos, bem como entre a arte e 
a filosofia, ao demonstrar que a arte também é conhecimento e que isto é evidente tanto em uma arte não referencial como na arte moderna (ARGULLOL, 1991).

O filósofo o faz por meio do questionamento da arte como uma alternativa para a experiência da verdade e para o esclarecimento da compreensão, incluindo-a na própria questão hermenêutica e inserindo a arquitetura no contexto das obras de arte, de maneira a situá-la em uma posição exemplar dentre as outras expressões artísticas devido à sua capacidade de cumprir funções estéticas, funcionais e artísticas de maneira harmônica. Gadamer propõe, assim, a noção de monumento arquitetônico.

O pensamento de Gadamer ressignifica as obras de arquitetura e propõe conexões entre os estudos da arquitetura e da filosofia. Assim, a investigação da noção de monumento arquitetônico abre novas perspectivas para pensar sobre a profunda relação homem-arquitetura, que vai além da esfera espaço-abrigo, uma vez que não se trata de uma arte meramente construtiva, criadora de espaços. A arquitetura é detentora de reflexos culturais de um povo, o que salienta um caráter fundamental da hermenêutica filosófica: sua ligação com as demandas da vida humana.

O foco da presente análise é realizar uma investigação acerca do conceito gadameriano de monumento arquitetônico e inserir a problemática hermenêutica no estudo da arquitetura, situando filosoficamente a noção de monumento na obra de Gadamer e contribuindo para a ampliação da visão arquitetônica entre os estudantes e profissionais de arquitetura, ao introduzir uma perspectiva filosófica. Partindo disso, torna-se interessante entender alguns pontos da hermenêutica e sua problemática, para adentrar na hermenêutica filosófica de Gadamer, e a noção de monumento arquitetônico. 


\section{UMA INTRODUÇÃO À HERMENÊUTICA}

A atual história da hermenêutica encontra-se ainda em construção, porém está entrelaçada tanto às antigas tradições das doutrinas da interpretação advindas da teologia protestante como a pensadores como Schleiermacher, Droysen e Dilthey, os quais contribuíram para a revitalização e o desenvolvimento de uma reflexão hermenêutica.

Desde o surgimento do termo, no século XVII, a hermenêutica dedica-se à arte da interpretação e, até o fim do século XIX, possuía intenção técnico-normativa, objetivando apresentar indicações metodológicas para as ciências declaradamente interpretativas, a fim de evitar a arbitrariedade nos ramos científicos que se preocupavam com o estudo de textos ou sinais (GRONDIN, 1999). Com a evolução dos tempos modernos, diversas definições sobre o termo reduziram seu conceito a um estágio histórico, ou seja, indicam um momento ou uma abordagem ao problema da interpretação, dando ênfase à exegese bíblica, à metodologia filológica e científica, entre outras (PALMER, 1997).

Grondin (1999) afirma ainda que a palavra hermenêutica é entendida de modo amplo e carrega enorme imprecisão e delimitação no sentido mais restrito de teoria da interpretação: para alguns, ela seria de natureza técnico-normativa e teria o intuito de ensinar o modo como se deve interpretar; para outros, seria de caráter fenomenológico, cabendo-lhe explicar como de fato se interpreta. O autor conclui que o objeto da teoria hermenêutica é o processo de interpretação e que ela se torna universal quando se leva em consideração que todas as atividades humanas têm como base o processo de compreensibilidade.

O aspecto universal do processo hermenêutico é citado por Gadamer (1997, p. 1) quando ele afirma que "entender e interpretar os textos não é 
somente um empenho da ciência, já que pertence claramente ao todo da experiência do homem no mundo" e está presente em diversas circunstâncias de entendimento, ou seja, desde a interpretação de um texto até o esforço de compreender novas culturas (KIDDER, 2013, p. 2).

Sendo assim, a hermenêutica se refere à interpretação em teoria e prática, podendo ser aplicada em tudo que possui um processo interpretativo e, consequentemente, de compreensão.

\title{
A PROBLEMÁTICA HERMENÊUTICA
}

Gadamer afirma:

\begin{abstract}
Com efeito, o problema posto pela hermenêutica pode ser definido pela seguinte questão: que sentido se deve dar ao fato de que uma única e mesma mensagem transmitida pela tradição seja, não obstante, apreendida sempre de maneira diferente, isto é, em relação à situação histórica concreta daquele que a recebe? (2003, p. 45)
\end{abstract}

Sendo assim, a hermenêutica se depara com diversos questionamentos sobre a interpretação: Qual o significado do texto? Qual a intenção do autor? Como interpretar esse texto sem modificar os significados atribuídos pelo autor? Como interpretar uma norma jurídica ou um texto sagrado? De acordo com Kidder (2013) esses questionamentos já eram perceptíveis nas filosofias de Platão, Aristóteles e nos escritos dos antigos retóricos, nos quais se indagavam sobre como as pessoas se entendiam ou como os escritos poderiam ser interpretados na ausência do autor.

Palmer (1997) afirma que o campo hermenêutico se apoia em dois focos distintos: a teoria da compreensão em sentido geral e o problema hermenêutico. O primeiro, segundo o autor, põe o questionamento da natureza da compreensão em um modo genérico e eventual, considerando 
mais o evento da compreensão do que a ideia.

Enquanto o segundo, o problema hermenêutico, "é uma instância específica do evento da compreensão: envolve sempre a linguagem, a confrontação com um outro horizonte humano, um acto de penetração histórica do texto" (PALMER, 1997, p. 77). Isto é, abrange outros aspectos tanto gerais quanto específicos, analisando, por exemplo, o contexto e o momento de relação com o presente, a fim de "formular uma teoria da compreensão linguística e histórica tal como funciona na interpretação do texto” (PALMER, 1997, p. 77).

No início de Verdade e método, Gadamer aproxima o problema hermenêutico à experiência filosófica, sendo esse tipo de experimentação uma das formas, segundo o autor, de se experienciar uma verdade que não pode ser verificada pelos meios científicos.

\section{O CÍRCULO HERMENÊUTICO}

O círculo hermenêutico, sugerido por Charles Taylor como solução para quando uma interpretação não é considerada adequada por outros que não chegaram a mesma concepção, se mostra como um processo em que diversas leituras culminarão no esclarecimento do texto. Como ainda afirma Taylor (1971, p. 18, tradução nossa):

O que estamos tentando estabelecer é uma certa leitura do texto ou expressões e o que nós recorremos como base para esta leitura só pode ser outras leituras. O círculo também pode ser formulado mediante a relação de partes e o todo: nós tentamos estabelecer a leitura de todo o texto e, para isso, recorremos à leitura de suas expressões parciais, e ainda, porque estamos lidando com significado e sentido, onde as expressões somente têm sentido ou não em relação a outras, as leituras de expressões parciais dependem das outras e, em última análise, do todo. 
Sendo assim, o círculo hermenêutico depende não somente da leitura que pretende ser interpretada, como também de conhecimentos anteriores e da relação entre as partes e o todo, uma vez que as partes constituem o sentido do todo, mas o sentido do todo define as partes individuais. Esse fato é apontado por Palmer como uma possível contradição lógica presente no círculo, no entanto, o autor afirma que o círculo não é um problema lógico:

Se temos que captar o todo antes de poder conhecer as partes, então nunca compreenderemos nada. E, no entanto, afirmamos que as partes tiram o seu sentido do todo. Por outro lado, não podemos certamente começar com um todo, não diferenciado em partes. (...) a lógica não valida totalmente as tarefas da compreensão. Há como que uma espécie de salto no círculo hermenêutico e compreendemos simultaneamente o todo e as partes. (1997, p. 94)

A necessidade de um conhecimento prévio daquilo que tem que ser compreendido torna-se outra contradição ilógica apresentada por Palmer (1997), porém é um aspecto necessário ao se levar em conta que, para que haja entendimento sobre um tema, é necessário possuir, até certo ponto, um conhecimento prévio dele, para que autor e leitor consigam partilhar da compreensão.

O círculo hermenêutico é, portanto, um processo que o leitor experiência quando busca entender o outro. Como diz Gadamer (1997, p. 402), o leitor está sempre em um ato de projetar e nesse ato surge um significado inicial que precisa ser revisado constantemente e novos projetos podem emergir na elaboração até que se chegue a uma "unidade do sentido". Dessa forma, o círculo permite acumular conhecimentos e leituras que podem ser utilizados em outros projetos de maneira produtiva e acumulativa. 


\section{A HERMENÊUTICA FILOSÓFICA DE GADAMER}

Com diversas ramificações que adentram o mundo jurídico e teológico, a hermenêutica filosófica, de data mais recente, dá nome à posição filosófica de Hans-Georg Gadamer que, influenciado por Heidegger, debruçou-se sobre as descobertas a respeito dos

(...)padrões de experiência e pensamento que ocorrem quando as pessoas procuram entender o mundo e umas às outras, quando interpretam textos ou outras expressões de significado e quando experenciam arte ou natureza como intrigante, agradável e significante. (KIDDER, 2013, p. 1, tradução nossa)

Por isso, Gadamer afirma como seu propósito a procura pela experiência da verdade e acredita que esta seja encontrada através da compreensão da filosofia, da arte e da história, sustentando que a dimensão hermenêutica da compreensão é universal (KIDDER, 2013, p. 2).

Outro aspecto da hermenêutica gadameriana é o questionamento quanto ao método. Em Verdade e método, tem-se que o problema da hermenêutica não é, desde sua origem histórica, relacionado ao método e nem tão somente ao empenho da ciência em entender e interpretar textos, já que toda a experiência do homem no mundo depende claramente de uma interpretação.

$\mathrm{Na}$ verdade, Gadamer clama que o importante no fenômeno hermenêutico não é a estruturação de uma metodologia pautada no rigor científico, mas a compreensão da tradição, que traz consigo juízos e verdades. Isto é, na visão gadameriana "a verdade zomba do homem metódico" (PALMER, 1997, p. 168) e ao afirmar isso, vai ao encontro de concepções anteriores de que a hermenêutica era a base metodológica para as ciências humanas e se firma como "uma tentativa filosófica que avalia a compreensão, como 
processo ontológico - o processo ontológico - do homem” (PALMER, 1997, p. 168).

Na primeira parte da obra, expressa-se uma crítica à consciência estética, reivindicando a arte como uma experiência da verdade válida para o homem no mundo. Segundo o autor, a consciência estética é consequência de uma interpretação errônea que a experiência estética proporciona:

O que chamamos de obra de arte e vivenciamos esteticamente repousa, portanto, sobre um desempenho de abstração. Na medida em que não se leva em consideração tudo em que uma obra se enraíza, como seu contexto de vida originário, isto é, toda função religiosa ou profana em que se encontrava e em que possuía seu significado, é aí que se tornará visível a "pura obra de arte". (GADAMER, 1997, p. 152)

Assim, a consciência estética retira da obra de arte todo o seu contexto originário alegando a pureza desta, quando, no ponto de vista gadameriano, a verdade revelada foi a das ciências, "o sujeito que contempla um objeto estético é uma consciência vazia recebendo percepções e gozando de certo modo, da imediatez de uma forma puramente sensível" (PALMER, 1997, p. 171). Esse processo de abstração da consciência estética produz um efeito que Gadamer denomina diferenciação estética. A experiência estética da arte a resume à forma, ao prazer estético, à satisfação perceptiva, desprovida de conhecimento, resultando na arte e no artista sem seu próprio lugar no mundo.

Por essa razão Gadamer (1997, p. 189) afirma que "a experiência da arte não poderá ser comprimida no descomprometimento da consciência estética”. Para ele, "essa visão negativa significa positivamente: a arte é conhecimento e a experiência da obra de arte torna esse conhecimento partilhável”, sendo necessário entender o conceito de experiência de maneira ampla a fim de entender a experiência da obra de arte como tal. 
Em meio a tais experiências, a arquitetura teria um papel exemplar e relevante na compreensão da verdade. Isto porque é uma obra de arte sempre situada no tempo e no espaço e abarca nela mesma o sentido próprio que, ao mesmo tempo, confronta-se com as novas possibilidades de sentido.

\section{A NOÇÃO DE MONUMENTO ARQUITETÔNICO}

Ao final da primeira parte de Verdade e método, Gadamer trata da arquitetura após discutir sobre a representação da ocasionalidade e da referência na pintura, afirmando sobre as obras de arte:

Pleiteiam por si mesmas o seu lugar, e mesmo quando estão deslocadas, p. ex., ao serem abrigadas num acervo moderno, não se consegue apagar nelas os indícios que remetem à sua determinação original. Pertencem a seu próprio ser, porque o seu ser é representação. (1997, p. 250)

A "arte da construção" constitui as formas de arte que se enquadram perfeitamente nesse critério, uma vez que seu "conteúdo próprio aponta para além de si mesmas, para o todo de uma conjuntura determinada por elas e para elas" (GADAMER, 1997, p. 250), e adquire uma posição exemplar em meio às outras obras de arte. É nesse contexto que Gadamer toma para si o termo "monumento arquitetônico".

Como monumento arquitetônico, na filosofia gadameriana, entendem-se os edifícios que possuem algo a ser levado em consideração pela ciência das artes. Este algo se refere a dois aspectos da arquitetura: o primeiro remete à tarefa arquitetônica de servir e de ocupar seu lugar em toda uma conjuntura, isto é, cumpre sua finalidade de maneira plena, mas também contribui visualmente em seu contexto urbano e paisagístico. 
Caso esteja de qualquer modo destoante de sua paisagem, não seria tida como tal.

Nesse sentido, a arquitetura torna-se uma "feliz solução" ao considerar os aspectos funcionais e espaciais. A partir disso, a construção "representa um verdadeiro crescimento do ser, isto é, é uma obra de arte”. Sendo assim, todo monumento arquitetônico teria algo a dizer, realizaria o movimento de "presentação" (BATISTA, 2013, p. 60), uma vez que é o reflexo da própria obra e, por isso, abre-nos seu mundo.

O segundo aspecto, inerente à natureza arquitetônica como obra de arte, trata de não somente representar uma solução artística para um determinado fim e com características vitais de suas demandas originais, mas também de mantê-las em sua solução, de modo que sejam conservadas e que continuem, ainda que a manifestação deste monumento arquitetônico esteja longe de sua origem, porém, há "algo nele que alude ao original” (GADAMER, 1997, p. 251).

Desta forma, quando esse propósito original se perde, o próprio edifício arquitetônico torna-se incompreensível. A partir deste aspecto, Gadamer afirma a arquitetura como forma artística que aponta de modo decidido para um caráter que não se identifica com a distinção estética. (BATISTA, 2013, p. 61)

Sendo assim, o edifício não pode simplesmente ser apreendido por uma consciência estética e, consequentemente, limitar-se à sua forma e à satisfação perceptiva, uma vez que, em casos como esse, Gadamer afirma que o monumento arquitetônico se reduziria ao objeto turístico ou fotográfico. 


\section{O OCASIONAL E O DECORATIVO}

A representação da pintura e a arquitetura são utilizadas para explanar, em Verdade e método, o fundamento ontológico do ocasional e do decorativo. Ao realizar essa indistinção no tratamento da arte e sua representação, aponta-se a crença de que o modelo de pensamento atua não somente nas outras formas de arte, mas na arquitetura em si (BATISTA, 2013).

A obra de arte não pode ser compreendida sob o ponto de vista da consciência estética e, por isso, alguns fenômenos tidos como problemáticos e que assumiam posição marginal até então têm sua devida atenção ao serem postos no centro das atenções. Exemplos disso são o portrait, a poesia em homenagem ou a alusão na comédia contemporânea (GADAMER, 1997). A partir disso, o autor introduz o caráter de ocasionalidade. Com ocasionalidade, Gadamer (1997, p. 234) "quer dizer que o significado continua se determinando, quanto ao conteúdo, a partir da ocasião em que ele é pensado, de maneira que ele contém mais do que sem essa ocasião".

Nessa perspectiva, Gadamer discute o sentido de representação tradicional no portrait, evidenciando a relação imagem-cópia e apresentando seu pensamento. Em suma, no sentido tradicional de representação, a cópia sempre se refere ao original e sua razão de ser se baseia na reprodução e na identificação deste e, por isso, se anula e perde sua função quando alcança seu fim. Já o original não se anularia.

No entanto, o fato da cópia ser uma imagem traz consigo uma autonomia, pois "um portrait quer ser entendido como portrait, mesmo quando a relação com o quadro original fica quase sufocada pelo próprio conteúdo da imagem do quadro" (GADAMER, 1997, p. 235). Dessa forma, estabelece-se uma nova relação entre a representação e a obra, na qual "acontece algo mais que a adequação ou confirmação de algo familiar, mas um 
acréscimo de ser, no sentido de que algo a mais acontece na relação com a própria obra" (BATISTA, 2013, p. 54).

A arquitetura é utilizada como exemplo em sua explicação sobre o caráter decorativo. O autor a qualifica como conformadora de espaço que recebe todas as atividades capazes de serem abarcadas e, consequentemente, todas as outras formas de representação como, por exemplo, a dança. Sendo assim, "torna vigente em toda parte o seu próprio ponto de vista. E este é o da decoração” (GADAMER, 1997, p. 252).

O uso da palavra "decoração" pode soar pejorativo, uma vez que remete à ornamentação e a apenas uma esfera da arquitetura, dentre tantas outras, bem como ao fato de que diversas linhas de pensamento arquitetônico negam a decoração e a ornamentação no edifício ao considerá-las superficialidades.

Gadamer usa "decorativo", no entanto, no sentido oposto - o que unifica um trabalho de arquitetura e, portanto, serve como um meio de resistência à superficialidade estética. Ele traça, aqui, o sentido vitruviano de "decorum", que se refere à adequação da forma ao seu significado e função. (KIDDER, 2013, p. 29, tradução nossa)

A adequação neste caso ocorre quando a arquitetura encontra seu lugar apropriado no seu contexto e serve ao seu propósito, sendo não somente conformadora de espaço que recebe toda ornamentação e as outras artes dentro de si, mas também por ser, em sua essência, decorativa. Sobre esse fato, Gadamer afirma:

A essência da decoração consiste em proporcionar essa dupla mediação, a de atrair sobre si a atenção do observador, satisfazer seu gosto, e ao mesmo tempo afastá-lo de novo de si, remetendo-o ao conjunto mais amplo do contexto vital a que ela acompanha. (1997, p. 253) 
Reafirma-se, portanto, o discurso inicial de que a arquitetura aponta para além de si mesma, bem como a capacidade não somente de construir espaços, mas também de influenciar fortemente os acontecimentos e as outras obras de arte que ocorrem neles, determinando seu papel fundamental entre as diversas expressões artísticas. Ao levar em conta a noção de "feliz solução" da tarefa arquitetônica e a caracterização de monumento, Gadamer não a reduz à simples ideia de funcionalidade, ao contrário, o autor integra o caráter artístico da arquitetura a sua essência funcional.

\section{JOGO, SÍMBOLO E FESTA}

Em A atualidade do belo: a arte como jogo, símbolo e festa, Gadamer faz uma reflexão a respeito da necessidade de justificativa e de legitimação da arte moderna em meio à ruptura com a tradição vista no século XIX, a qual resultou na perda do lugar do artista no mundo. Antes entendido por meio da sua relação de lugar e significância com o mundo, integrado à sociedade, agora "todo artista vivia na consciência de que a comunicação entre ele e os homens para quem criava havia deixado de ser algo evidente" (GADAMER, 1991, p. 17, tradução nossa).

Nesse momento de crise, novas perspectivas se abrem para a arte atual e sua reflexão, na qual "a arte hoje constitui uma tarefa para o pensamento" (GADAMER, 1991, p. 19, tradução nossa). As artes tradicionais e modernas, segundo o autor, devem ser consideradas conjuntamente e o aspecto questionador das novas expressões artísticas permitem um novo questionamento da própria filosofia:

O estranhamento causado pela arquitetura moderna e sua renovada tentativa de ruptura com as formas mais tradicionais transforma-se, de acordo com o argumento 
de Gadamer, numa nova possibilidade de questionamento da própria filosofia. O que significa dizer que o pensamento não pode ignorar o caráter próprio de seu tempo e situação, mas, ao contrário, deve clarificar as referências com o passado e sua tradição. (BATISTA, 2013, p. 68)

Nesse sentido, Gadamer caracteriza a arte e a arquitetura como vinculadas a alguma época e lugar. Por isso elas devem ser investigadas levando em conta a consideração histórica da arte passada e moderna. Ele apresenta três conceitos como base antropológica para a experiência da arte: jogo, símbolo e festa.

O conceito de jogo está relacionado com a função elementar da vida humana, uma vez que se trata do componente lúdico da cultura e esta característica é um elemento essencial da vida. O jogo implica um movimento de vai e vem, repetitivo e contínuo, sem nenhum propósito, bem como a existência de certa estrutura ou conjunto de regras que, embora não seja necessariamente sua finalidade, o jogador trata como se fosse.

Quando, em correlação com a experiência da arte, falamos de jogo, jogo não significa aqui o comportamento ou muito menos o estado de ânimo daquele que cria ou daquele que usufrui e, sobretudo, não significa a liberdade de uma subjetividade que atua no jogo, mas o próprio modo de ser da obra de arte. (GADAMER, 1997, p. 174)

O que está em evidência é a própria relação entre o jogador e a obra de arte, inseridos no processo lúdico. O jogador participa no jogo e é parte dele, não é apenas um mero observador distante da obra. No entanto, "o sujeito do jogo não são os jogadores, porém o jogo, através dos que jogam, simplesmente ganha representação" (GADAMER, 1997, p. 176), dessa maneira, "um trabalho de arte transforma o jogo em uma estrutura específica que coordena a experiência de sua audiência” (KIDDER, 2013, p. 21, tradução nossa). A estrutura do jogo funciona, portanto, como indicativo da compreensão hermenêutica da obra. 
O símbolo, por sua vez, é uma espécie de passaporte para uma época antiga que permite reconhecer, no presente, um antigo conhecido. A palavra, de origem grega, remete a um pedaço de memória, algum objeto entregue por um anfitrião a um hóspede para que algum descendente deste seja reconhecido caso peça abrigo anos depois. O símbolo, dessa forma, seria um fragmento que remete a uma unidade.

A experiência do símbolo seria, portanto, o ser individual que se representa como um fragmento de um ser que o complementa, ou seja, refere-se a algo mais geral, a um todo: "toda a experiência da obra de arte sempre tem um caráter de remetimento enquanto significação a ser compreendida” (BATISTA, 2013, p. 74). O monumento arquitetônico, por sua vez, também remete a algo mais geral, que vai além de si mesmo, apontando para uma totalidade de sentido.

O terceiro conceito introduzido por Gadamer, é a noção de festa. A festa, segundo o autor, é comunidade, é a apresentação da comunidade em sua forma mais completa e é feita para todos. Ela reúne e congrega, podendo ser considerada uma arte: a arte de saber celebrar. As experiências em uma festa, pode-se dizer, se assemelham às da obra de arte: o mesmo silêncio necessário para um discurso ocorre ao admirar um monumento artístico; assim como na festa, a obra de arte congrega pessoas com uma mesma intenção, que os une e os impede de dispersarem-se em vivências individuais (GADAMER, 1991).

O caráter temporal da festa remete à estrutura temporal da obra de arte: "ao celebrar uma festa, a festa está sempre e em todo momento ali. E nisto consiste precisamente o caráter temporal de uma festa: ser celebrada e não se distingue na duração de uma série de momentos sucessivos" (GADAMER, 1991, p. 47). Dessa forma, a festa tem em si uma espécie de retorno e permite uma experiência diferente do tempo. 
A obra de arte, e consequentemente o monumento arquitetônico, também tem seu próprio tempo, "não está determinado pela duração calculável de sua extensão no tempo e sim por sua estrutura temporal própria” (GADAMER, 1991, p. 49), sem se desprender de sua historicidade. O monumento arquitetônico reúne em seu interior pessoas e obras e, ao exercer a função de abrigar, a festa acontece e saímos transformados dela.

\section{A NOÇÃO GADAMERIANA DE MONUMENTO ARQUITETÔNICO APLICADA À ARQUITETURA}

A hermenêutica filosófica de Gadamer permitiu novas perspectivas sobre a obra de arte e, consequentemente, a arquitetura. Dalibor Vesely tem papel fundamental nas discussões da teoria da arquitetura. Arquiteto, filósofo e professor, o antigo aluno de Gadamer dedicou seu trabalho a promover o papel da hermenêutica no discurso arquitetônico e nos desenvolvimentos representativos da arquitetura no século XX.

Vesely (2004, p. 27, tradução nossa), em Architecture in the age of divided representation, visa "entender a capacidade da arquitetura de criar, ou pelo menos iniciar, a formação de um espaço comunicativo”. Este espaço, no entanto, não seria estruturado apenas para cumprir seu papel funcional, mas também em um sentido mais abrangente: como portadora de significado e capaz de "reverberar através de outros níveis de cultura e ajudar a incorporá-los” (VESELY, 2004, p. 27, tradução nossa). Há, portanto, a busca pela humanização da arquitetura, resistindo à redução à funcionalidade prática, característica do período conhecido como pré-moderno.

Há uma aproximação de Gadamer à noção de monumento arquitetônico ao constatar essa abrangência de sentido, significado e representação da arquitetura. Além disso, ao considerar como obrigação da arquitetura 
atender a aspectos funcionais, culturais e expressivos, Vesely toma emprestado o conceito de Gadamer de uma arquitetura que aponta para além de si mesma e que tem em si uma "feliz solução".

Outras discussões mais recentes sobre a hermenêutica e a arquitetura, no Brasil, vêm sendo intermediadas por Carlos Antônio Leite Brandão, professor na Universidade Federal de Minas Gerais. Em seu escrito Monumentalidade e cotidiano: a função pública da arquitetura, Brandão se refere, primeiramente, à temporalidade do monumento:

Monumento e cotidiano remetem, em primeira instância, às dimensões da eternidade e do dia a dia; do que é raro e do que se repete; do que remete à memória, à lembrança, e se destina também ao futuro (como na etimologia de monumento) e do que serve ao presente e ao corriqueiro comum (como na etimologia do "cotidiano"). Queria abordar este binômio, nesta primeira parte, referindo-o a essas duas dimensões do tempo. (BRANDÃO, 2006, p. 3)

Nesse sentido, Brandão se aproxima de Gadamer ao destacar o caráter ocasional do monumento arquitetônico, bem como sua própria temporalidade. Entende-se a arquitetura como veículo de significado quando descreve o templo grego clássico, utilizado como exemplo de monumento arquitetônico, uma vez que "cuida de fazer da arquitetura veículo de mensagens históricas, éticas e culturais que ultrapassam o que é arquitetura ‘strictu sensu'” (BRANDÃO, 2006, p. 3).

As questões levantadas por Brandão, em consonância com o pensamento gadameriano, também trazem possibilidades de reflexão sobre a abordagem da arquitetura no que tange ao patrimônio cultural edificado. Não seria o monumento arquitetônico de Gadamer uma possibilidade de interpretação e justificativa para a proteção do patrimônio histórico construído? 
A hermenêutica filosófica considera aspectos funcionais, espaciais, temporais, psicológicos e afetivos no que tange ao monumento arquitetônico, características que são utilizadas como fundamentação para a determinação de políticas patrimoniais. Sendo assim, Gadamer traz a consolidação de ideias defendidas atualmente no meio, como, por exemplo, a obra entendida em um contexto e a representação de uma solução artística com demandas originais.

Uma abordagem hermenêutica da arquitetura traz diversas possibilidades:

Uma abordagem hermenêutica da arquitetura descobre o padrão hermenêutico do pensamento e experiência em diversas áreas do empreendimento arquitetônico. Pode ser encontrado no processo criativo do arquiteto e na apreciação estética da criação do arquiteto. Pode ser encontrado na busca por entender tradições arquitetônicas e escritos sobre arquitetura. Pode ser encontrado na maneira que todos os que colaboram no empreendimento arquitetônico - os clientes, a comunidade, os investidores, os reguladores, a os designers - entendem uns aos outros e trabalham juntos. (KIDDER, 2013, p. 1)

As reflexões apresentadas aqui comprovam a amplitude do monumento arquitetônico e seu questionamento filosófico, abrindo novas perspectivas para o estudo da arquitetura.

\section{CONCLUSÃO}

O pensamento filosófico de Hans-Georg Gadamer está inserido em um contexto de mudanças histórico-filosóficas no século XIX. A arte se desvencilhava das concepções tradicionais e o artista entrou em crise ao tentar reconhecer seu lugar no mundo. Em meio a esse cenário, os questionamentos sobre a verdade e a interpretação passam a enfrentar novos 
desafios e a arte surge como uma alternativa de experiência da verdade.

Situada em uma posição exemplar diante das outras formas de arte, o monumento arquitetônico passa a ter papel importante nessa busca pela verdade. A arquitetura, como obra de arte, conformadora de espaço que abriga todas as demais expressões artísticas, traz consigo aspectos que vão além da estética: cumpre a funcionalidade e apresenta uma solução artística para uma demanda, mantendo-a no tempo.

Gadamer atribui a esse exemplar da arquitetura, características como jogo, símbolo e festa, além do ocasional e do decorativo, os quais não se limitam ao vocábulo pejorativo utilizado em muitas conversas com arquitetos e colegas da construção civil como sinônimo de trivialidades.

Ao estudar a perspectiva gadameriana sobre a arquitetura, pode-se aferir como uma grande contribuição para os estudos da disciplina o seu olhar para o aspecto mais humanista da arte da construção: o jogo, o tempo, a história e o significado são características presentes apenas quando existe a figura humana na busca por entendimento. Tal fato pode ser levado adiante por arquitetos e urbanistas ao promover trabalhos que considerem o usuário não só como expectador, mas também como alguém que usufrui, experiência e interpreta o espaço construído, indo muito além de uma captação apenas visual.

É importante mencionar a conclusão de Kidder (2013, p. 122) sobre um arquiteto engajado hermeneuticamente:

Então o que é isto, finalmente, que distingue um arquiteto hermeneuticamente engajado? É, alguns podem dizer, um tipo de sensibilidade - onde o jogo pode ser apropriado, onde pistas para resolver problemas pode estar à espreita em fontes linguísticas e históricas, momentos onde ouvir pode ser mais apropriado do que falar, momentos onde se deve questionar as próprias premissas antes de questionar as dos outros. Isto envolve conhecimento, apesar de não se chamar um arquiteto hermeneuticamente engajado baseado simplesmente no co- 
nhecimento do corpo. Não é exatamente uma questão de experiência ou habilidade, apesar, novamente, de que eles tenham seu papel a cumprir. É uma questão de participação, de exploração, de reconhecimento, antecipação, indagação, jogando com possibilidades.

Percebe-se, com essa passagem, a relação entre filosofia e a sensibilidade do arquiteto, em que conceitos filosóficos podem influenciar na aplicação prática e estudo da arquitetura. Entender as dimensões da arquitetura, além das disciplinas técnicas, proporciona, portanto, a aquisição de novos conhecimentos e, consequentemente, uma nova perspectiva. 


\section{REFERÊNCIAS}

ARGULLOL, R. Introducción: el arte después de la "muerte del arte". In: GADAMER, Hans-Georg. La actualidad de lo bello. Barcelona: Paidós, 1991. p. 10-23.

BATISTA, G. S. A relevância da arquitetura no pensamento de Gadamer. 2013. 123 f. Tese (Doutorado em Filosofia) - Departamento de Filosofia, Pontifícia Universidade Católica do Rio de Janeiro, Rio de Janeiro. 2013.

BRANDÃO, C. A. Monumentalidade e cotidiano: a função pública da arquitetura. MDC: Revista de Arquitetura e Urbanismo, Belo Horizonte, 31 mar. 2006. Disponível em: [https://bit.ly/2qrzSW3]. Acesso em: [15 de ago. 2017].

GADAMER, H-.G. Verdade e método: traços fundamentais de uma hermenêutica filosófica. Tradução de Flávio Paulo Meurer. 2. ed. Petrópolis: Vozes, 1997.

O problema da consciência histórica. Tradução: Paulo Cesar Duque Estrada. 2. ed. Rio de Janeiro: Editora FGV, 2003.

La actualidad de lo bello. Barcelona: Paidós, 1991.

GROMBRICH, E. H .A história da arte. Tradução: Álvaro Cabral. 16. ed. Rio de Janeiro: LTC, 2012.

GRONDIN, J. Introdução à hermenêutica filosófica. Tradução de Benno Dischinger. São Leopoldo: Ed. Unisinos, 1999.

KIDDER, P. Gadamer for architects. New York: Routledge, 2013.

PALMER, R. E. Hermenêutica. Tradução de Maria Luísa Ribeiro Ferreira. Lisboa: Edições 70, 1997.

TAYLOR, C. Interpretation and the sciences of man. The Review of Metaphysics, Washington, v. 25, n. 1, p. 3-51, 1971.

VATTIMO, G. O fim da modernidade: niilismo e hermenêutica na cultura pós-moderna. Tradução de Eduardo Brandão. São Paulo: Martins Fontes, 1996.

VESELY, D. Architecture in the age of divided representation: the question of creativity in the shadow of production. Cambridge, MA: MIT Press, 2004. 